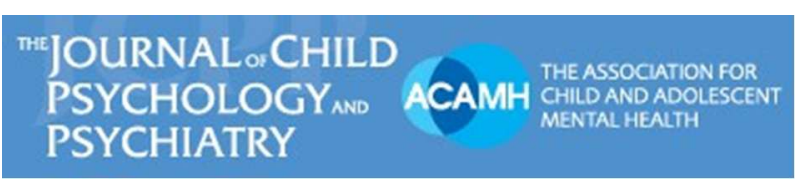

\title{
The association of attention deficit hyperactivity disorder with socio-economic disadvantage: Alternative explanations and evidence.
}

\begin{tabular}{|r|l|}
\hline Journal: & Journal of Child Psychology and Psychiatry \\
\hline Manuscript ID: & JCPP-2013-00259.R2 \\
\hline Danuscript Type: & JCPP Original Article \\
\hline Complete List of Authors: & $\begin{array}{l}\text { Russell, Ginny; University of Exeter, ESRC Centre for Genomics in Society } \\
\text { Ford, Tamsin; University of Exeter, Institute for Health Services Research, } \\
\text { Medical School } \\
\text { Rosenberg, Rachel; Institute of Education, Centre for Longitudinal Studies } \\
\text { Kelly, Susan; University of Exeter, School of Social Science }\end{array}$ \\
\hline Key Words: & $\begin{array}{l}\text { ADHD, Child development, Longitudinal studies, Social class, Socio-cultural } \\
\text { influence }\end{array}$ \\
\hline &
\end{tabular}




\title{
The association of attention deficit hyperactivity disorder with socio-economic disadvantage: Alternative explanations and evidence.
}

\author{
Ginny Russell, ESRC Centre for Genomics in Society (Egenis) \& Institute of Health \\ Research, University of Exeter Medical School, Exeter, UK \\ Tamsin Ford, \\ Institute of Health Research, University of Exeter Medical School, Exeter, UK \\ Rachel Rosenberg, \\ Centre for Longitudinal Studies, Institute of Education, London, UK \\ Susan Kelly, \\ ESRC Centre for Genomics in Society (Egenis), School of Social Science, University of \\ Exeter, UK
}

Abbreviated title: Socio-economic status and children with ADHD

\author{
None of the authors have any conflict of interest. \\ Correspondence to. Ginny Russell, University of Exeter Medical School, Veysey Building, Salmon Pool \\ Lane, Exeter, UK EX4 4PJ. phone 01392 265138, e mail g.russell@ex.ac.uk.
}




\section{The association of attention deficit hyperactivity disorder with socio-economic disadvantage: Alternative explanations and evidence.}

\section{Abstract \\ Background}

Studies throughout Northern Europe, the USA and Australia have found an association between childhood attention deficit hyperactivity disorder (ADHD) and socio-economic disadvantage. We report further evidence for the association and review potential causal pathways that might explain the link.

\section{Method}

Secondary analysies of a UK birth cohort (the Millennium Cohort Study, N=19,519) was used to model the association of ADHD with socio-economic disadvantage and assess evidence for several potential explanatory pathways. The case definition of ADHD was a parent-report of whether ADHD had been identified by a medical doctor or health professional when children were seven years old.

\section{Results}

ADHD was associated with a range of indicators of social and economic disadvantage including poverty, housing tenure, maternal education, income, lone parenthood and younger motherhood. There was no evidence to suggest childhood ADHD was a causal factor of socio-economic disadvantage: income did not decrease for parents of children with ADHD compared to controls over the seven year study period. No clinical bias towards labelling ADHD in low SES groups was detected. There was evidence to suggest parent attachment /family conflict mediated the relationship between ADHD and SES.

\section{Discussion}

Although genetic and neurological determinants may be the primary predictors of difficulties with activity level and attention, aetiology appears to be influenced by socio-economic situation. 


\section{Introduction}

Childhood a Attention $\underline{\mathrm{d}} \bigoplus$ eficit $\underline{h} H y p e r a c t i v i t y \underline{\mathrm{d}} \bigoplus$ Hisorder (ADHD) has been reported to be more prevalent among socio-economically disadvantaged groups in many regions of the developed world. Studies from the US (Akinbami, Liu, Pastor, \& Reuben, 2011; Froehlich et al., 2007; Pastor \& Rueben, 2008; St Sauver et al., 2004), the UK (Ford, Collishaw, Meltzer, \& Goodman, 2007) and Scandinavian countries (Bøe, Øverland, Lundervold, \& Hysing, 2012; Hjern, Weitoft, \& Lindblad, 2010; Paananen et al., 2012), as well as in Australia (Sciberras, Ukoumunne, \& Efron, 2011) and Germany (Döpfner, Breuer, Wille, | Erhart, \& Ravens-Sieberer, 2008), have all found an association between increased childhood ADHD or behavioural symptoms of ADHD, and socio-economic disadvantage. A recent systematic review, although focussed on treatments for ADHD, nevertheless-noted that both symptoms and diagnosis of ADHD are more common among those from a low socioeconomic status (SES) background (Charach et al., 2011).

ADHD is diagnosed when a child demonstrates inattentive, hyperactive and impulsive behaviours in multiple settings, that which have emerged prior to age seven and causes functional impairment (APA, 2000). Potential explanations for the association can be classified into two types. Firstly 'real' effects: in lower socio-economic groups children truly have higher symptom levels. Secondly, 'labelling' effects : greater awareness and access to health care in some groups or differential reporting about the same level of difficulties between groups (Boyle et al., 2011). Figure 1 provides a schematic illustration of the causal pathways that may explain the link between childhood ADHD and low SES.

\section{Insert Figure 1}

Proponents of health inequalities models have tended to position disease as an effect of socio-economic disadvantage (Najman et al., 2004), often operating through differential exposure (Pathways 1 and 2, Figure 1). In this pathway, higher rates of ADHD in groups with greater socio-economic disadvantage are mediated through differential exposure. Such

| exposures could be perinatal, prenatal ${ }_{2}$ or occur during childhood. A systematic review of pre- and perinatal risk factors for ADHD only implicated exposure to tobacco smoke in utero | as a suspected risk factor (Linnet et al., 2003). Several studies have shown association between smoking in pregnancy and increased risk of ADHD (Schothorst \& Van Engeland, 
1996; Thapar et al. 2003) although other research suggests genetic and socio-economic confounders partially or entirely account for the effect (e.g. Lindblad \& Hjern, 2010).

Exposures later in childhood have also been linked to ADHD phenotypes and socio-economic disadvantage ${ }_{2}$; for example, numerous studies have examined the link between parenting and ADHD, several describing unattached parenting or family conflict as risk factors (Deault, 2010; Johnston \& Mash, 2001). Pathway 2, Figure 1 illustrates influence of mediating factors in childhood, of which family conflict is the focus in our analysis, although there is evidence for various other risk factors during this stage. For example a randomised double blinded placebo-controlled trial found augmented food additives in the diet led to increased hyperactivity in children (McCann et al, 2007).

Pathways 3 and 4 (Figure 1) illustrate genetic and neurological explanations of causality. An average estimate of heritability of ADHD was derived at 76\%, from 20 twin studies (Faraone et al., 2005); although the effect of gene-environment interactions are hard to separate from genetic influences. Adoption studies suggest ADHD has a strong genetic component; even these designs cannot discount the influence of prenatal environmental risks (Thapar, Cooper, Eyre \& Langley, 2013). No design to date has separated inheritance due to shared environmental influences from genetic influences convincingly. Specific genetic risks identified so far for ADHD tend to have small effect sizes or to be rare and often increase risk of many other types of psychopathology. Thapar and colleagues (2013) propose that the separation of genetic from environmental influences is a false dichotomy: ADHD is a multifactorial complex condition with many genes acting together to affect predisposition while environment acts on the genotype for the ADHD phenotype to present itself. Genetic predisposition in parents may lead to inherited predisposition in children with expression triggered by environmental factors (Pathway 3). ADHD symptoms in parents cause them difficulties in maintaining relationships and lead to poor socio-economic outcomes (Pathway 4), as seen in recent studies of outcome at adulthood (e.g. Galéra et al., 2013). In the genetic confounding scenario, parents of children with ADHD have a genetic predisposition to hyperactive and inattentive behaviours themselves, and are therefore more likely to a) more tikely to pass on such a predisposition to their children and b) suffer socio-economic disadvantage described above. 
Pathways 4 and 5 (Figure 1) illustrate pathways that conceptualise ADHD in children-as in itself a cause of low SES (reverse causality). A meta-analysis by Doshi and colleagues (2012) estimated national productivity losses due to family members with children who had ADHD at $\$ 33 \mathrm{~B}$ to $\$ 43 \mathrm{~B}$ per year in the US. Other health economists have included direct measures of income lost to families of children with ADHD,-- such as time parents spend away from work (Kvist, Neilson and Simonsen, 2013), increased childcare expenses, work loss and stress-related illnesses (Pelham, Foster, \& Robb, 2007). Carers of children with ADHD, most often women, report that whilst supporting their children they have limited capacity to obtain high-paid employment (Litt, 2004). In all these studies, having a child with ADHD is framed as cause of low SES as it limits ability to find work and sustain social networks, leading to lost income and social exclusion.

Pathways 6 and 7 (Figure 1) illustrate association due to labelling bias. Here ${ }_{2}$ clinicians would be more likely to diagnose ADHD in low SES groups (pathway 6, Figure 1). In pathway 7, families with socio-economic disadvantages would be more likely to report ADHD symptoms, perhaps prompted by teachers or difficulties at school.

Where possible, we aimed to assess evidence for some examples of potential pathways in Figure 1 through secondary analysis of data from the Millennium Cohort Study (MCS). Because of the longitudinal nature of the study, it was possible to seek evidence for the reverse causality model (Pathway 5) by assessing the effect of having a child with ADHD on socio-economic factors over seven years. The questions tested were:-

- Are parental relationships more likely to dissolve after childhood ADHD has been identified?

- Does family income decrease for families with a child with ADHD relative to those with a child without?

It was also possible to check for labelling effects through comparison of parent-reported symptom levels with identification by health professional/diagnosis (Pathways 6/7):

- Do doctors and health professionals diagnose ADHD more often in socioeconomically deprived groups, compared to parent and teacher reports of ADHD symptoms?

Finally, two risk factors consistently implicated in the literature were tested for mediating effects. These were smoking in pregnancy (an early environmental exposure representing 
Pathway 1) and lack of parent attachment /family conflict (an example of later 'exposure' or differential family context, representing Pathway 2). The questions raised were:

- Does low SES mean that mothers are more likely to smoke in pregnancy, leading to greater rates of ADHD?

- Does low SES affect parenting adversely ${ }_{2} \div$ increasing the odds of a child having ADHD?

These exposures were intended to be illustrative examples of plausibility of mediation by differential exposure to risk factors as a pathway from socio-economic disadvantage to ADHD.

\section{Methods}

\section{Sample}

The MCS has followed 19,519 UK children born between 2000 and 2002, via surveys and direct cognitive testing, carried out by trained interviewers face-to--face in family homes. Information was gathered from the first MCS survey when children were 9 months_old, and three, five and seven years of age: four sweeps of data collection. Informed parental consent was obtained at each stage of the study; the MCS ethical review gives details (Shepherd, 2012). Sample design in MCS was geographically clustered and disproportionately stratified to over-sample children from ethnic minorities, and disadvantaged neighbourhoods (details of sample design are in Hansen, 2012). Attrition is a problem common to all longitudinal cohorts and over-sampling was used to ensure adequate representation of the population at later ages (Plewis, 2007). Standardised weightings were applied to make the data representative of the UK population, and these adjusted results for the effects of attrition by age 7: approximately $72 \%$ of participating families were responding by this stage. $f$ We excluded children who had a statement of special needs $(n=318)$ as a proxy for other | disorders (i.e. children with autism, hearing problems, conduct disorder were likely to have statements) because being diagnosed with alternative problems could confound the | relationship between ADHD and SES (as symptoms of other disorders often co-occur with hyperactivity and some are linked to SES). Children who were twin or triplet siblings were also omitted as the study was under-powered to examine within-family variance. At sweep 4 the mean age was 7.2 years $(\mathrm{SD}=0.2$; age range $=6.3$ to 8.2 ). The included sample size in this study who had reported on their child's ADHD status was 13305. 
Details of fieldwork, coding and questionnaires for MCS measures used are documented at length in Hansen (2012). Extensive documentation and all questionnaires used to generate MCS data are freely available, together with the dataset itself, and can be accessed via the MCS website.

\section{Measure of ADHD diagnosis}

Parent-reports of ADHD diagnosis by a medical doctor or health professional were taken as ADHD case definition $(n=187)$. This measure has been used to estimate the prevalence of ADHD (Pastor \& Rueben, 2008; Akinbami et al., 2011) using US data from National Health Interview Survey (NHIS). The MCS used the NHIS question to record ADHD status: during face to face interviews, parents or carers were asked:

- Has a doctor or health professional ever told you that (sample child) had attention deficit hyperactivity disorder (ADHD)?

In line with other studies (e.g. Boyle et al., 2011) a positive answer to the above question was taken as representative of ADHD diagnosis. Families who answered 'don't know' or refused to answer were excluded from the analysis. In MCS, after weighting, $1.5 \%$ of children were reported as having been identified /diagnosed with ADHD by sweep 4 in MCS.

\section{Measures of SES}

Measures of socio-economic status taken at all sweeps included parents' highest educational qualification, social class (NS-SEC seven class structure; ONS, 2013), family size and type of housing tenure: in the UK, social housing is let at low rents and on a secure basis to people in housing need. Equivalised family income was measured at each sweep (adjusted for the number of children per family), with households classed as living in poverty at sweep 4 if their income was equal to or less than $60 \%$ of the median household income for the UK, the definition of poverty set by the UK government (below $£ 236$ per week). Family structure (either lone parent or couple) was reported at each sweep. Married couples were more economically advantaged in MCS than lone parent families (Kiernan \& Mensah, 2009). The first MCS survey recorded the children's birth weight from the UK Birth Registration and Maternity Hospital Episode Data and the age of mother at childbirth. An 'index of SES' was also created from variables measured at sweep 1 that were relatively stable over time: fathers' social class, mothers' social class, and paternal and maternal education.- $+\underline{T}$ to test tobacco use 
in utero as a mediator it was necessary to assume the SES index would have preceded | pregnancy 18 months previously: assumption of stability; Cole \& Maxwell, 2003). This index of SES was calculated by taking the mean values of these measures using an incremental score of 1 for each decrease in rank. If data were missing, the mean across the number of variables for which valid data were recorded was taken. As a check we generated a second SES index from factor analysis of the same measures (one factor resulted). Correlation between these two indices of SES was $99.5 \%$.

\section{Risk factors}

Records of whether mothers smoked during pregnancy were taken when children were aged 9 months old. Pregnant mothers were classified as smokers or non-smokers $\bar{y}_{-}$Mmissing data were not analysed. The Child-Parent Relationship Scale (CPRS) adapted from the StudentTeacher Relationship Scale (Pianta, 1995) was used to measure attachment. The CPRS is a 15 item self-administered rating scale, with responses on a 5 point Likert scale. Items were derived from attachment theory and the attachment Q-set, (Waters \& Dean, 1985). The items involve the respondent's feelings and beliefs about the relationship with the child, and about the child's behaviour toward the parent. CPRS was measured in MCS sweep 2 (mean age children=3.1 years, $\mathrm{SD}=0.2$ ) and used to generate 'Conflict' and 'Closeness' scores. The 'closeness' score was reversed and scores were combined to create a family conflict / distant parent score. Approximately $98 \%$ of respondents were mothers. -

\section{Symptoms of ADHD}

The Strengths and Difficulties Questionnaire (SDQ) is a behavioural screening questionnaire for children aged 4-16 (Goodman, 2001) that includes a sub-scale for hyperactivityinattention and the accompanying impact of problematic behaviours. The SDQ was administered to both parents and teachers at sweep 4 in MCS. The four measures of SDQ teacher/parent reported hyperactivity-inattention and impact for each child were considered as indicative of ADHD symptoms as they have been strongly correlated with ADHD in several other studies (e.g. Ullebo, Posserud, Heiervang, Gillberg \& Obel, 2011). Children's clinicians were not informed of SDQ research ratings.

\section{Analysis}

First, the association between the outcome of ADHD diagnosis and a range of indicators of socio-economic disadvantage, including maternal education level, poverty, income, lone 
parenthood, family size, birth weight and being a younger mother, and index of SES was established using logistic regression. Standardised weights accounted for attrition and disproportionate sampling in MCS. The odds ratios (OR) from the analyses indicate the increase in odds of being identified with ADHD corresponding to an incremental increase in each predictor.

The reverse causality hypothesis (Pathway 5, Figure 1) was that having a child with ADHD causes greater socio-economic disadvantage and therefore predicts less increase in income for families of children with ADHD and more family breakdown, and was modelled using change in income and family structure. Linear regression was used to compare the increase in | income between families whose study child had ADHD diagnosedis and families whose child did not have ADHD or a statement of SEN. All cases where family income was recorded at | all four time points; (when the study child was aged 9 months, 3 years, 5 years and 7 years) were included ( $\mathrm{n}=8193)$. Further sensitivity analysis utilized propensity score matching to define a control group who had comparable socio-economic disadvantages to families with a child with ADHD when their children were 9 months old. Nearest neighbour matching was used to define controls, with income at 9 months, child's sex, mother's highest qualification, and lone parenthood as conditioning variables. Study children in control families had neither diagnosis of ADHD, nor statement of SEN by age 7. Linear regression was again used to compare the increase in family income between cases and controls over the seven year study period. In addition, change in the number of single parent families was plotted for children with ADHD over time.

To test for labelling effects, the association between the outcome of ADHD diagnosis and measures of SES was again modelled using logistic regression, the regression adjusting for the effects of parent/teacher reported hyperactivity-inattention symptoms and their impact $(\mathrm{N}$ ranged from 7826 to 8015 : only cases with complete data for all values were included). This was to establish whether the association between clinical ADHD diagnosis and socioeconomic disadvantage existed independently of levels of parent-teacher reported symptoms, i.e. a clinical labelling bias.

Two risk factors that have been repeatedly identified in the literature, smoking in pregnancy, and family conflict/distant parenting, were tested for mediating effects. These were hypothesised to mediate the association between ADHD and SES. For mediation to be 
inferred, the predictor must precede the mediator, which in turn must precede the outcome, in this case, SES first, mediator second, ADHD third (Cole \& Maxwell, 2003). The mediation analysis computed total effects (overall association between index of SES and ADHD with no mediation), indirect effect (for SES-ADHD pathway mediated by measure of interest) and direct effect sizes (for pathway in mediation model not flowing through measure of interest) calculated from a product of coefficients, using bootstrapping (300 replications) to estimate bias corrected confidence intervals (CIs), as recommended by Preacher and Hayes (2008). Figure 3 illustrates the causal pathways tested. The indirect effects and direct effects add up to the total effect. The coefficients were standardised to compare direct and indirect effects.The Stata command for binary mediation (Ender, 2011) was-used to calculate the indirect effects uses $\mathrm{A}$ a combination of linear regression with logit models. Where the CIs from the indirect effects (the effect of the predictor on the outcome via the mediator) does not cross zero, the analysis provided evidence that mediation had occurred. Syntax for all analyses is available on request.

\section{Results}

ADHD is strongly associated with a range of indicators of social and economic disadvantage in this cohort, including poverty, housing tenure, income, lone parenthood, index of SES and being a younger mother. Table 1 shows descriptive statistics for families who have cohort children with and without a diagnosis of ADHD.

\section{Insert Table 1}

As Table 1 illustrates, a larger proportion of children with ADHD diagnosis came from families below the poverty line than in the UK population as a whole. The mean equivalised income for households with an ADHD study child was $£ 324$ per week as opposed to $£ 391$ for families without a child with ADHD diagnosis, and the odds of parents who owned their own houses having children with ADHD were roughly a third the odds for those who were in social housing. The mean age of mothers at delivery was 26 years for children who would later have ADHD diagnosis and 28 years for those without: the odds of having a child with ADHD were significantly higher for younger mothers. Children whose muthers withhad no qualifications were over-more than twice as likely to have children with ADHD thanas those with degrees. Lone parents were more likely to have children with ADHD diagnosis than those families with two live-in parents. Greater socio-economic disadvantage as measured by 
the index of SES was also associated with ADHD. There was no association between ADHD and birth weight or family size in MCS.

\section{Insert Figure 2}

\section{Checking for reverse causality}

Change in income over time between parents with and without a study child with ADHD was plotted (Figure 2). Overall, income showed a linear trend to increase over time, with income increasing on average $£ 13.93$ per year per family who had a child with ADHD (95\% CI 8.66$19.19 ; p<.001$ ), and $£ 10.99$ for the rest of the sample (95\% CI 9.92-12.06; $p<.001$ ). As Figure 2 illustrates, there was no evidence of a comparative decrease in income over time for families with a child with ADHD compared to those without. In fact there was a slight increase in income for families with a child with ADHD, compared to the rest of the population over the seven year period, but the difference in income increase was not significant. Results provided no evidence to support the reverse causality model in relation to loss of income.

After propensity score matching, change in income with time was also not significantly different between the two groups. Control families’ initial average weekly income was $£ 244$ as opposed to $£ 249$ for families with a child with ADHD. Over the seven year study period, income increased by $£ 11.63$ per year (95\% CI, 7.13-16.13) for controls. Families with a child | with ADHD child did slightly better, as noted above, although confidence intervals overlapped substantially.

According to the reverse causality hypothesis, a child with ADHD might put additional strain on family resources leading to increase in marital breakup. ADHD is rarely identified before age 3; hyperactive and inattentive behaviours are highly prevalent, and considered 'normal' in many toddlers, not just those who go on to a diagnosis of ADHD (Einarsdottir, 2008). We therefore hypothesised an increase in marital breakdown in families after age 3 during primary school years, when ADHD behaviours become problematic. In MCS there was no discernible increase in percentage of lone parent families in the ADHD group after the age of 3. There was an association between lone parenthood and childhood ADHD, but this was true at 9 months and at 3 years, before ADHD behaviours are-typically become challenging. 


\section{Insert Table 2}

\section{Checking for clinical labelling bias.}

Logistic regression reported in Table 1 was repeated, but adjusted for parent and teacher rated symptoms of ADHD. The remaining association between ADHD and SES is reported in Table 2. No association of clinical diagnosis with social disadvantages remained independently of parent-teacher rated symptom level: adjustment accounted for every significant association between ADHD diagnosis with measures of SES. Results suggest that socio-economic labelling practices do not differ substantially between doctor's diagnosis of ADHD and parent-teacher ratings of symptoms of ADHD.

\section{Checking for mediation}

Both smoking during pregnancy and family conflict/distant parenting were independently associated with all the measures of SES. Where more conflict and less closeness was reported between parent and child, families were more likely to experience social or economic disadvantage. Distant parenting/family conflict was also associated with having a child with ADHD, OR=1.11, 95\% CI, (1.08-1 .13), $\mathrm{p}<0.001$; even after adjustment for measures of socio-economic disadvantage $\mathrm{OR}=1.09,95 \% \mathrm{CI},(1.05-1.21), \mathrm{p}<0.001$.

In MCS, 5,239 mothers reduced their tobacco use during pregnancy with 2,327 mothers giving up smoking, and 1,664 continuing to smoke: these were more likely to be from low SES backgrounds. Mothers were more likely to have a child with ADHD if they smoked during pregnancy: $\mathrm{OR}=2.26,95 \% \mathrm{CI}(1.54-3.31) \mathrm{p}<001$. Smoking in pregnancy was still independently associated with ADHD after adjusting for salient measures of $\mathrm{SES}_{2}$ although its effect was weaker, OR=1.53, 95\% CI, (1.03-2 .29) $\mathrm{p}=0.036$.

\section{Insert Figure 3}

Figure 3 shows the effect sizes for mediated and non-mediated pathways from SES to ADHD. The CIs of the indirect effect through parenting do not cross zero, which suggests that parenting may act as a mediator between SES and ADHD. This is a necessary condition for claiming the predictor, mediator and outcome variables are causally related. In contrast, the model does not support smoking in pregnancy as a potential mediator. 


\section{Discussion}

This study detected a higher prevalence of ADHD among socio-economically disadvantaged groups, a finding that concurs with results from a wide range of other studies (Akinbami et al., 2011; Döpfner et al., 2008; Ford et al., 2007; Froehlich et al., 2007; Pastor \& Rueben, 2008; Sciberras et al., 2011; St Sauver et al., 2004). To our knowledge, the only systematic review that has touched on this subject was focussed on treatment of ADHD and not symptoms or diagnosis of ADHD per se (Charach et al., 2011). A recent systematic review of child mental health more generally found socio-economically disadvantaged individuals were two to three times more likely to develop mental health problems (Reiss, 2013).

Models from health economics have conceptualised ADHD as a disorder with socioeconomic consequences for families (Doshi et al. 2012; Litt, 2004). The current study found no evidence for such a reverse causality hypothesis. Kvist et al. (2013) analysed labour supply (i.e, number of days taken off work by mother or father per year) and found parents of children with ADHD took 2-4 additional days off work compared to controls. The UK MCS data did not report on number of days absent from work $\cdot \dot{-}$ Eeven if it differed for the parents of children with ADHD, it did not impact growth in family income for these families over the | ten years studied ${ }_{2}$ which is considered a more influential measure of SES than labour supply.

We found no support for the hypothesis of over-reporting by clinicians about children of lower SES: parent teacher rated symptom levels were equally elevated in disadvantaged groups as reports of clinical diagnosis were elevated. while clinical diagnosis of ADHD was elevated in socio-economically disadvantaged groups, our results foundsuggest that parentrated and teacher-rated symptoms were equally elevated in disadvantaged groups. That is, pathway 6 did not appear greater than pathway 7 in our schematic model (Figure 1). It is | possible that all parties over-report and over--diagnose ADHD in disadvantaged groups, but as socio-economic disadvantage subsequently seems to act as a barrier to treatment after | clinical diagnosis of ADHD is made ${ }_{2}$ this seems unlikely.

Tobacco use in pregnancy is a suspected risk-factor for ADHD (Linnet et al., 2003) and there is a strong relationship between low SES and tobacco use during pregnancy, but it did not act as a mediator in our analysis. Our results suggest lack of parent involvement/family conflict may be mediating the influence of SES on the outcome of ADHD, and lack of parental involvement/family conflict is more common among families of low SES both in our data 
and elsewhere (Aber, Bennett, -Conley, \& Li, 1997). With this mediator added to the equation, the relationship between the measures of SES and ADHD was partially accounted for, but not totally explained.

Parental conflict/ attachment in early childhood operated as a mediator, which suggests that family context /'exposures' continue to have an influence throughout the lifecourse.

Lifecourse models do not necessarily rule out critical periods of development. Children may be more susceptible at some stages of development to certain risk factors, but differential effects may continue as children mature, and be mitigated by better circumstances later. The focus of this paper is not mediator specific, but attempts to examine plausibility of mediation and other competing pathways as explanations. The developing child is influenced by an interconnected set of environmental influences and contexts, some related to SES, such as nutrition, disease, socio-cultural values, poverty, parenting and peer influences: each may influence outcomes more or less at different developmental stages.

Our study has a number of strengths. The large sample size and longitudinal nature of the dataset has allowed us to infer causal direction by tracking over time. Furthermore, the measures used are well established and MCS has recorded detailed socio-economic indicators. The greatest limitation to the design was that we were not able to account for genetic predisposition and its potential confounding effect. It was not possible to weight the data in analysis of mediation; however, unweighted regression models are often robust in large datasets (see Wolke et al., 2009). Although the analysis explored parental attachment/family conflict as a simple mediating factor, parenting itself may be influenced by shared genetic predisposition, as well as the effect of having a hyperactive child, hence the bi-directional nature of the arrow in Figure 1, pathway 2. There is evidence to suggest treatment with Methylphenidate improves family functioning, for example (Barkley, Karlsson, Pollard, \& Murphy, 1985). The influence and character of parenting is likely more complex than acting as a simple mediating factor.

Overall, results provided no evidence for the reverse causality model, or of labelling bias: instead, findings suggest that mediators linked to SES or genetic confounds may provide the most useful framework to explain why ADHD occurs more often in socio-economically disadvantaged groups (Pathways 1-4, Figure 1). The aetiology of ADHD is likely to be a complex interplay of genetic and environmental factors, some linked to socio-economic 
disadvantage. Bronfenbrenner (1979) posits a contextual systems model of child development that considers proximal and distal factors that affect how individuals with innate differences react to given environments. As the association between childhood ADHD and socioeconomic disadvantage appears increasingly robust, it becomes important to search for possible explanations for the link. Meta-analysis across many studies is required to substantiate the extent of the association across cultures. Our findings need to be replicated in other datasets, at other developmental stages, and indicate the need for research to examine further potential pathways, especially controlling for genetic predisposition.

\section{Acknowledgements}

This work was funded by the ESRC's Secondary Data Analysis Initiative. We also acknowledge funding from the National Institute for Health Research (NIHR) Collaboration for Leadership in Applied Health Research and Care (CLAHRC) for the South West Peninsula. The views expressed in this publication are those of the author(s) and not necessarily those of the NHS, the NIHR or the Department of Health in England. We would like to thank the Millennium Cohort Study families for their time and cooperation, as well as the Millennium Cohort Study team at the Institute of Education, London, UK, and finally, Dr. Obioha Ukoumunne for his helpful advice on analysis.

Correspondence to. Ginny Russell, University of Exeter Medical School, Veysey Building, Salmon Pool Lane, Exeter, UK EX4 4PJ. phone 01392 265138, e mail g.russell@ex.ac.uk.

\section{References}

Aber, J. L., Bennett, N. G., Conley, D. C., \& Li, J. (1997). The effects of poverty on child health and development. Annual Review of Public Health, 18, 463-483.

Akinbami, L. J., Liu, X., Pastor, P. N., \& Reuben, C. A. (2011). Attention deficit hyperactivity disorder among children aged 5-17 years in the United States, 19982009. NCHS Data Brief, (70), 1-8. 
American Psychiatric Association (2000) Diagnostic and Statistical Manual of Mental Disorders (DSM-IV), (4th Ed., Text Revision). Washington: American Psychiatric Press.

Barkley, R. A., Karlsson, J., Pollard, S., \& Murphy, K. (1985). Developmental changes in the mother-child interactions of hyperactive children: effects of two doses of Ritalin. $J$ Child Psychol Psychiatry, 13, 631-638.

Bøe, T., Øverland, S., Lundervold, A. J., \& Hysing, M. (2012). Socioeconomic status and children's mental health: results from the Bergen Child Study. Social Psychiatry and Psychiatric Epidemiology, 47(10), 1557-1566.

Boyle, C. A., Boulet, S., Schieve, L. A., Cohen, R. A., Blumberg, S. J., Yeargin-Allsopp, M., Visser, S., et al. (2011). Trends in the prevalence of developmental disabilities in US children, 1997-2008. Pediatrics, 127(6), 1034-1042.

Bronfenbrenner, U. (1979). The ecology of human development: Experiments by nature and design (New Ed.). Cambridge, MA: Harvard University Press.

Charach, A., Dashti, B., Carson, P., Booker, L., Lim, C. G., Lillie, E \& Schachar, R. (2011). Attention deficit hyperactivity disorder. Effectiveness of treatment in at-risk preschoolers. Comparative Effectiveness Reviews, No. 44

Cole, D. A., \& Maxwell, S. E. (2003). Testing mediational models with longitudinal data: questions and tips in the use of structural equation modeling. Journal of Abnormal Psychology, 112(4), 558-577.

Deault, L. C. (2010). A systematic review of parenting in relation to the development of comorbidities and functional impairments in children with attention- 
deficit/hyperactivity disorder (ADHD). Child Psychiatry and Human Development, 41(2), 168-192.

Döpfner, M., Breuer, D., Wille, N., Erhart, M., \& Ravens-Sieberer, U. (2008). How often do children meet ICD-10/DSM-IV criteria of attention deficit-/hyperactivity disorder and hyperkinetic disorder? European Child \& Adolescent Psychiatry, 17 Suppl 1, 59-70.

Doshi, J. A., Hodgkins, P., Kahle, J., Sikirica, V., Cangelosi, M. J., Setyawan, J \& Neumann, P. J. (2012). Economic impact of childhood and adult attention-deficit/hyperactivity disorder in the United States. Journal of the American Academy of Child and Adolescent Psychiatry, 51(10), 990-1002.e2.

Einarsdottir, J. (2008). Teaching children with ADHD: Icelandic early childhood teachers' perspectives. Early Child Development and Care, 178(4), 375-397.

Ender, P. (2011) binary_mediation: Mediation with binary mediator and/or response variables. UCLA: Statistical Consulting Group. Retrieved from: www.ats.ucla.edu/stat/stata/faq/binary_mediation.htm (July 2013)

Faraone, S. V., Perlis, R. H., Doyle, A. E., Smoller, J. W., Goralnick, J. J., Holmgren, M. A., \& Sklar, P. (2005). Molecular genetics of attention-deficit/hyperactivity disorder. Biological Psychiatry, 57(11), 1313-1323.

Ford, T., Collishaw, S., Meltzer, H., \& Goodman, R. (2007). A prospective study of childhood psychopathology: independent predictors of change over three years. Social Psychiatry \& Psychiatric Epidemiology, 42(12), 953-961.

Froehlich, T. E., Lanphear, B. P., Epstein, J. N., Barbaresi, W. J., Katusic, S. K., \& Kahn, R. S. (2007). Prevalence, recognition, and treatment of attention-deficit/hyperactivity 
disorder in a national sample of US children. Archives of Pediatrics \& Adolescent Medicine, 161(9), 857-864.

Galéra, C., Bouvard, M.-P., Lagarde, E., Michel, G., Touchette, E., Fombonne, E., \& Melchior, M. (2012). Childhood attention problems and socioeconomic status in adulthood: 18-year follow-up. British Journal of Psychiatry, 201(1), 20-25.

Goodman, R. (2001). Psychometric properties of the strengths and difficulties questionnaire. Journal of the American Academy of Child and Adolescent Psychiatry, 40(11), 13371345.

Hansen, K. (2012) The Millennium Cohort Study: A guide to the datasets $\left(7^{\text {th }}\right.$ Ed.) Centre for Longitudinal Studies: Institute of Education: London. Available at http://www.cls.ioe.ac.uk/page.aspx?\&sitesectionid=851\&sitesectiontitle=Welcome+to + the + Millennium + Cohort + Study, accessed July 2013

Hjern, A., Weitoft, G., \& Lindblad, F. (2010). Social adversity predicts ADHD-medication in school children - a national cohort study. Acta Pcediatrica, 99(6), 920-924.

Johnston, C., \& Mash, E. J. (2001). Families of children with attention-deficit/hyperactivity disorder: review and recommendations for future research. Clinical Child and Family Psychology Review, 4(3), 183-207.

Kiernan, K. E., \& Mensah, F. K. (2009). Poverty, maternal depression, family status and children's cognitive and behavioural development in early childhood: A longitudinal study. Journal of Social Policy, 38(04), 569.

Kvist, A. P., Nielsen, H. S., \& Simonsen, M. (2013). The importance of children's ADHD for parents' relationship stability and labor supply. Social Science \& Medicine, 88, 3038. 
Lindblad, F., \& Hjern, A. (2010). ADHD after fetal exposure to maternal smoking. Nicotine \& Tobacco Research, 12(4), 408-415.

Linnet, K. M., Dalsgaard, S., Obel, C., Wisborg, K., Henriksen, T. B., Rodriguez, A., Kotimaa, A., Moilanen, I., Thomsen, P.H., Olsen, J., \& Jarvelin, M.R. (2003). Maternal lifestyle factors in pregnancy risk of attention deficit hyperactivity disorder and associated behaviors: Review of the current evidence. American Journal of Psychiatry, 160(6), 1028-1040.

Litt, J. (2004). Women's carework in low-income households: The special case of children with attention deficit hyperactivity disorder. Gender Society, 18(5), 625-644.

McCann, D., Barrett, A., Cooper, A., Crumpler, D., Dalen, L., Grimshaw, K., Elizabeth Kitchin, E., Lok, K., Porteous, L., Prince, E., Sonuga-Barke, E. O Warner, J. \& Stevenson, J. (2007). Food additives and hyperactive behaviour in 3-year-old and 8/9year-old children in the community: A randomised, double-blinded, placebocontrolled trial. The Lancet, 370(9598), 1560-1567.

Najman, J. M., Aird, R., Bor, W., O’Callaghan, M., Williams, G. M., \& Shuttlewood, G. J. (2004). The generational transmission of socioeconomic inequalities in child cognitive development and emotional health. Social Science \& Medicine, 58(6), $1147-1158$.

Office for National Statistics, ONS (2013). The National Statistics Socio-economic Classification Scheme. Fareham, UK. User manual available at http://www.ons.gov.uk/ons/guide-method/classifications/current-standardclassifications/soc2010/soc2010-volume-3-ns-sec--rebased-on-soc2010--user$\underline{\text { manual/index.html. }}$ 
Paananen, R., Santalahti, P., Merikukka, M., Rämö, A., Wahlbeck, K., \& Gissler, M. (2012). Socioeconomic and regional aspects in the use of specialized psychiatric care: A Finnish nationwide follow-up study. European Journal of Public Health.

Pastor, P. N., \& Rueben, C. A. (2008). Diagnosed attention deficit hyperactivity disorder and learning disability: United States, 2004-2006. US Department of Health and Human Services, Centres for Disease Control and Prevention. Vital and Health Statistics Series 10, no. 237.

Pelham, W. E., Foster, E. M., \& Robb, J. A. (2007). The economic impact of attentiondeficit/hyperactivity disorder in children and adolescents. Ambulatory Pediatrics, $7(1$, Supplement), 121-131.

Pianta, R. C. (1995). Child-Parent Relationship Scale. Charlottesville, VA: University of Virginia Press.

Plewis, I. (2007). The Millennium Cohort study: Technical report on sampling. Centre for Longitudinal Studies, London. Retrieved from http://www.esds.ac.uk/doc/5350/mrdoc/pdf/mcs technical report_on sampling 4th edition.pdf

Preacher, K. J., \& Hayes, A. F. (2008). Asymptotic and resampling strategies for assessing and comparing indirect effects in multiple mediator models. Behavior Research Methods, 40(3), 879-891.

Reiss, F. (2013). Socioeconomic inequalities and mental health problems in children and adolescents: A systematic review. Social Science \& Medicine, 90, 24-31.

Schothorst, P. F., \& Van Engeland, H. (1996). Long-term behavioral sequelae of prematurity. Journal of the American Academy of Child \& Adolescent Psychiatry, 35(2), 175-183. 
Sciberras, E., Ukoumunne, O. C., \& Efron, D. (2011). Predictors of parent-reported attentiondeficit/hyperactivity disorder in children Aged 6-7 years: A national longitudinal study. Journal of Abnormal Child Psychology, 39(7), 1025-1034.

Shepherd, P. (2012). Millennium Cohort Study: Ethical review and consent. CLS, London: UK.

St Sauver, J. L., Barbaresi, W. J., Katusic, S. K., Colligan, R. C., Weaver, A. L., \& Jacobsen, S. J. (2004). Early life risk factors for attention-deficit/hyperactivity disorder: A population-based cohort study. Mayo Clinic Proceedings. Mayo Clinic, 79(9), 1124 1131.

Thapar, A., Cooper, M., Eyre, O., \& Langley, K. (2013). Practitioner review: What have we learnt about the causes of ADHD? Journal of Child Psychology and Psychiatry, 2013 $54(1): 3-16$

Thapar, A., Fowler, T., Rice, F., Scourfield, J., Van den Bree, M., Thomas, Harold, G. \& Hay, D. (2003). Maternal smoking during pregnancy and attention deficit hyperactivity disorder symptoms in offspring. The American Journal of Psychiatry, $160(11), 1985-1989$.

Ullebo, A.K,, Posserud, M.B., Heiervang, E., Gillberg, C., Obel, C. (2011) Screening for the attention deficit hyperactivity disorder phenotype using the Strength and Difficulties Questionnaire. European Child and Adolescent Psychiatry, 20(9):451-8.

Waters, E., \& Dean, K. (1985). Defining and assessing individual differences in attachment relationships: Q-methodology and the organization of behavior in infancy and early childhood. In In I. Bretherton \& E. Waters (Eds.), Growing points of attachment 
theory and research (Vols. 1-209, Vol. 50, pp. 41-65). Chicago: University Of Chicago Press.

Wolke, D., Waylen, A., Samara, M., Steer, C., Goodman, R., Ford, T., \& Lamberts, K. (2009). Selective drop-out in longitudinal studies and non-biased prediction of behaviour disorders. The British Journal of Psychiatry, 195(3), 249-256. 


\section{Key points}

- Childhood attention deficit hyperactivity disorder (ADHD) and its behavioural symptoms have often been associated with socio-economic disadvantage.

- In a 2008 sample representative of the UK, ADHD was associated with a range of indicators of social and economic disadvantage.

- The study provided no evidence to suggest childhood ADHD was a causal factor of socio-economic disadvantage and no evidence of labelling bias.

- Parent attachment /family conflict apparently mediated the relationship between ADHD and SES. 
Figure 1: Simplified schematic illustration of the potential explanations for the association of ADHD with socio-economic disadvantage

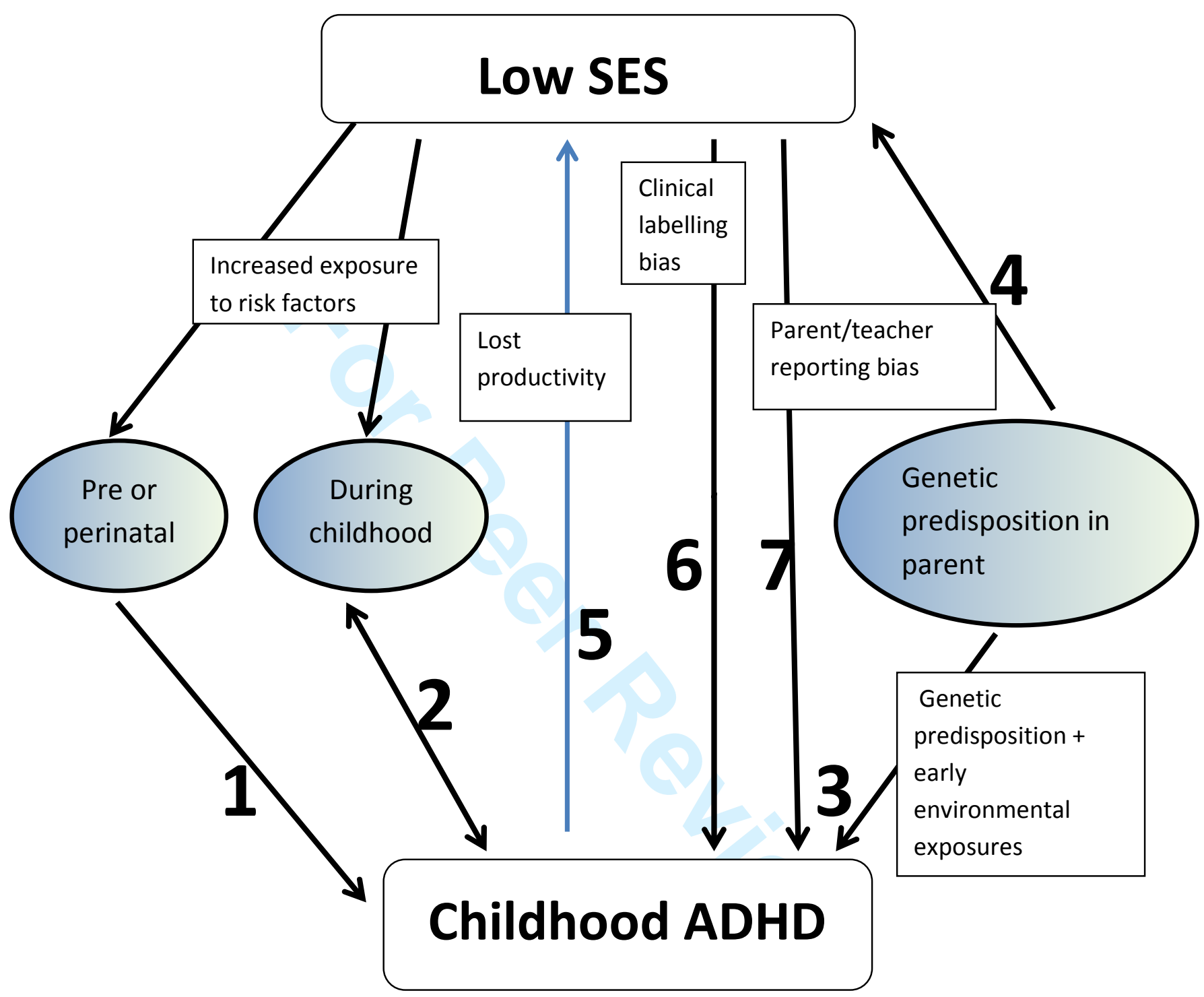

Pathway 1,2 mediation by risk factor

Pathway 3,4 genetic confounding

Pathway 4,5 reverse causality model

Pathway 6 labelling/identification effects (clinicians)

Pathway 7 reporting effects (parents/teachers) 
Figure 2: Comparison of mean equivalised income over time in MCS families with study child who had diagnosis of ADHD $(n=187)$ and families whose study child had no ADHD diagnosis $(\mathrm{N}=13,000+)$.

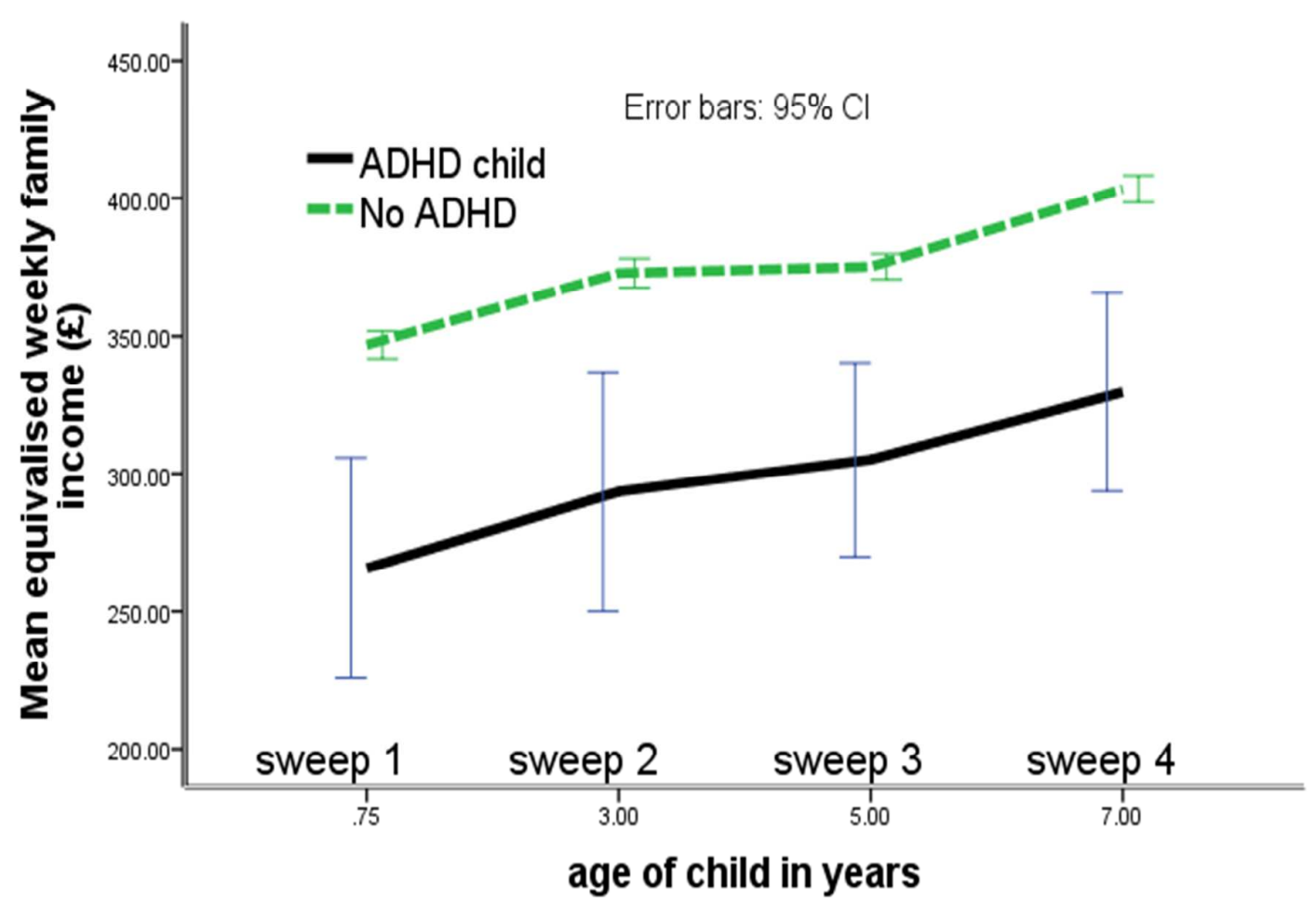

37

38

39

40

41

42

43

44

45

46

47

48

49

50

51

52

53

54

55

56

57

58

59

60 
Figure 3: Causal pathway with effect sizes for mediated and non-mediated pathways from SES to ADHD i) no mediator ii) two mediators.

i) Sweep 1

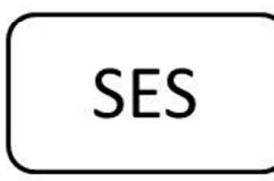

predictor

Sweep 4

ii)

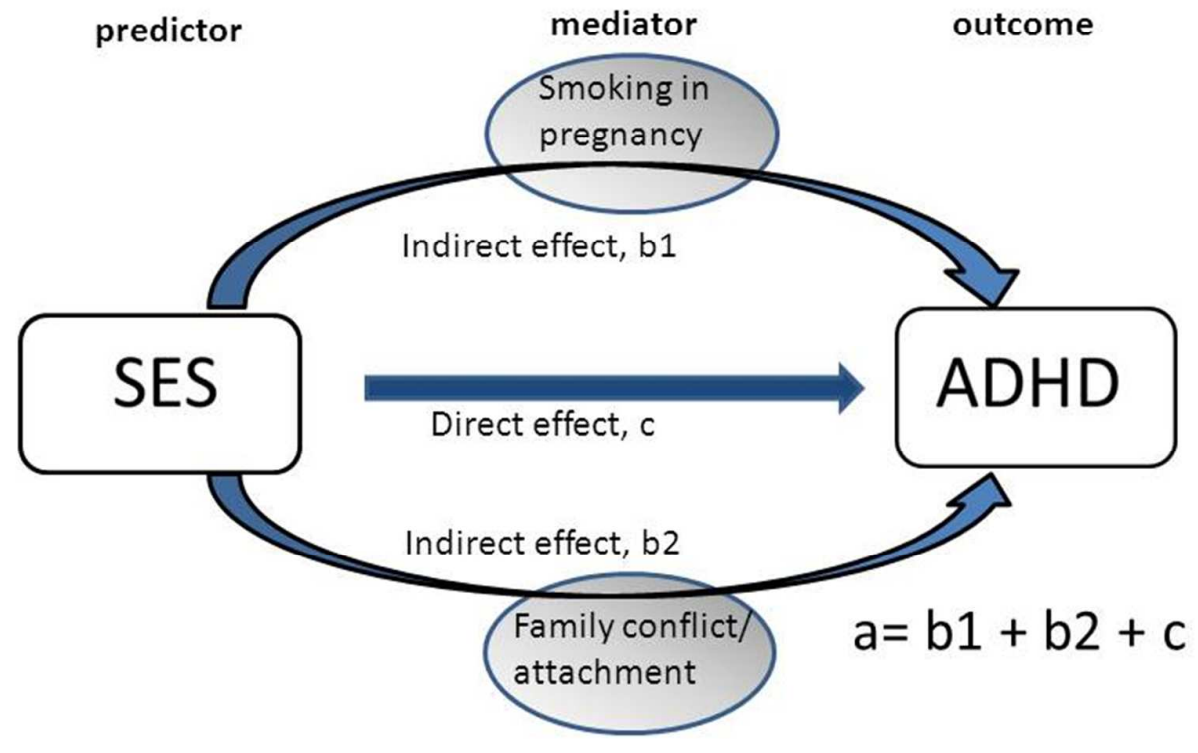

Observed coefficients
$\mathrm{a}=0.181,95 \% \mathrm{Cl}(.091, .274)^{*}$
b1 $=0.029,95 \% \mathrm{Cl}(-.009, .069)$
b2 $=0.045,95 \% \mathrm{Cl}(.032, .056)^{*}$
$\mathrm{C} \quad=\quad 0.108,95 \% \mathrm{Cl}(.003, .205)^{*}$ 
Table 1: The association of indicators of socio-economic disadvantage with ADHD in the Millennium Cohort

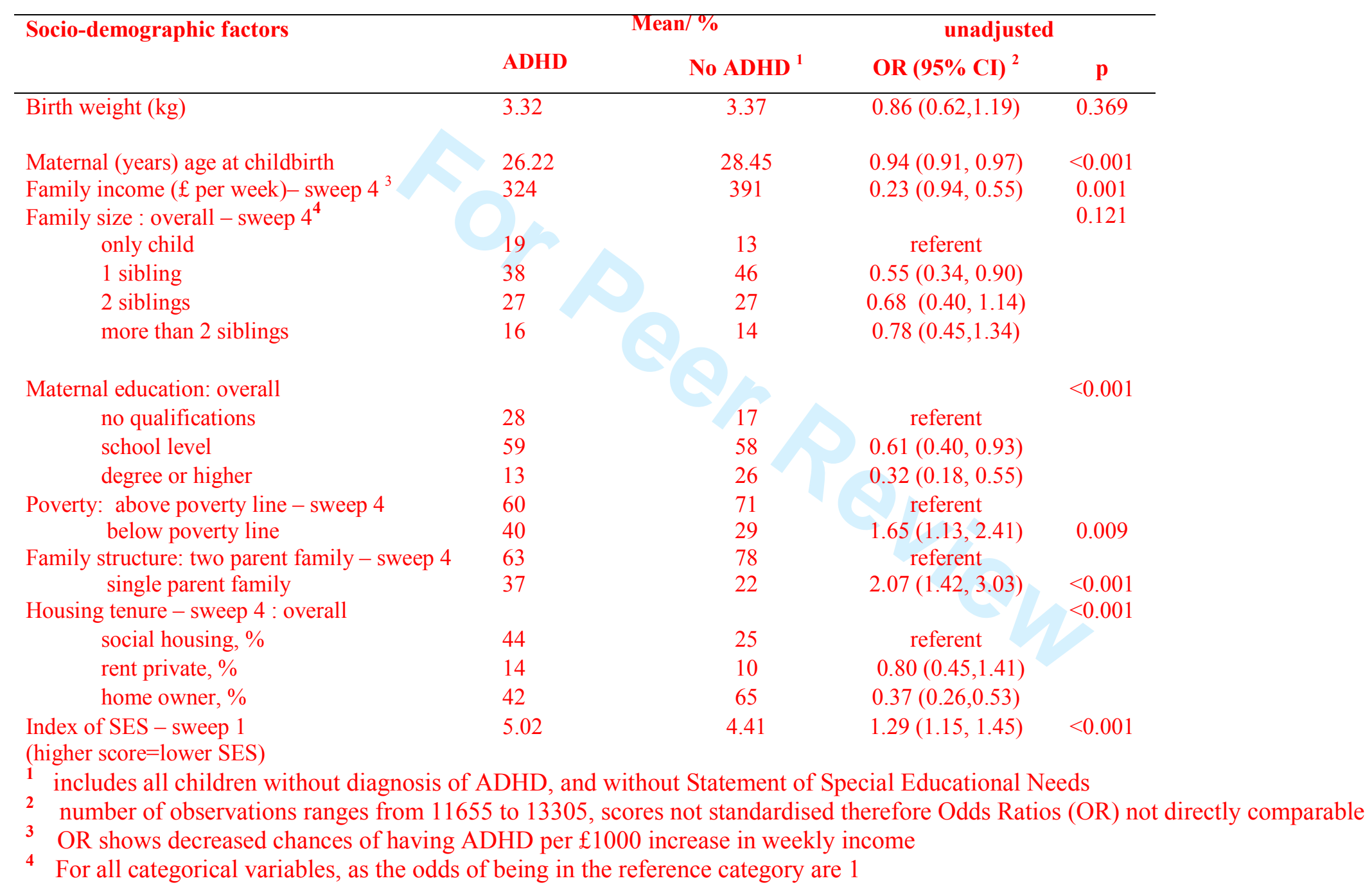


Table 2: The association of indicators of socio-economic disadvantage with ADHD adjusted for parent and teacher SDQ hyperactivity \& impact subscales.

\begin{tabular}{|c|c|c|}
\hline Socio-demographic factors & $\begin{array}{c}\text { OR }(95 \% \text { CI })^{1} \\
\text { adjusted }\end{array}$ & $\mathbf{p}$ \\
\hline Birth weight (kg) & $0.96(0.59,1.57)$ & 0.891 \\
\hline Maternal (years) age at childbirth & $0.99(0.95,1.03)$ & 0.721 \\
\hline Family income (£1000)- sweep 4 & $0.92(0.26,3.19)$ & 0.892 \\
\hline $\begin{array}{l}\text { Family size : overall - sweep } 4 \\
\text { only child } \\
1 \text { sibling } \\
2 \text { siblings } \\
\text { more than } 2 \text { siblings }\end{array}$ & $\begin{array}{c}\text { referent } \\
1.04(0.44 .2 .46) \\
1.36(0.64,2.87) \\
0.85(0.32,2.27)\end{array}$ & $\begin{array}{l}0.924 \\
0.409 \\
0.752\end{array}$ \\
\hline $\begin{array}{c}\text { Maternal education: overall } \\
\text { no qualifications } \\
\text { school level } \\
\text { degree or higher }\end{array}$ & $\begin{array}{c}\text { referent } \\
0.69(0.35,1.34) \\
1.17(0.55,2.46)\end{array}$ & $\begin{array}{l}0.275 \\
0.680\end{array}$ \\
\hline $\begin{array}{l}\text { Poverty: above poverty line - sweep } 4 \\
\text { below poverty line }\end{array}$ & $\begin{array}{c}\text { referent } \\
1.07(0.62,1.86)\end{array}$ & 0.803 \\
\hline $\begin{array}{l}\text { Family type: --sweep } 4 \\
\text { dual parent } \\
\text { single parent family }\end{array}$ & $\begin{array}{c}\text { referent } \\
1.11(0.61,2.03)\end{array}$ & 0.734 \\
\hline $\begin{array}{l}\text { Housing tenure }- \text { sweep } 4 \text { : overall } \\
\text { social housing, } \% \\
\text { rent private, } \% \\
\text { home owner, } \% \\
\text { Index of SES: - sweep } 1\end{array}$ & $\begin{array}{c}\text { referent } \\
1.12(0.44,2.86) \\
0.94(0.55,1.62) \\
1.03(0.86,1.24)\end{array}$ & $\begin{array}{l}0.806 \\
0.829 \\
0.648\end{array}$ \\
\hline
\end{tabular}

